\title{
GTINDIA2013-3563
}

\section{A Comparative Study On The Synthesis And Properties Of Yttria Stabilized Zirconia (YSZ) And Lanthana Doped YSZ Plasma Sprayed Thermal barrier coatings}

\author{
S.T. Aruna \\ Surface Engineering Division \\ Council of Scientific and Industrial Research - \\ National Aerospace Laboratories, \\ HAL Airport Road, Bangalore \\ 560017, India
}

\author{
N. Balaji \\ Surface Engineering Division \\ Council of Scientific and Industrial Research - \\ National Aerospace Laboratories, \\ HAL Airport Road, Bangalore \\ 560017, India
}

\section{ABSTRACT}

Ceramic thermal barrier coatings (TBCs) have been used for decades to extend the life of combustors and high turbine stationary and rotating components. By using TBCs, one can increase the operating temperature and in turn the performance of gas turbines or diesel engines can be increased. At present, thermal barrier coatings (TBCs) of $\mathrm{Y}_{2} \mathrm{O}_{3}$ partially stabilized $\mathrm{ZrO}_{2}$ (YPSZ) films are widely used to protect hot section parts of aircraft and land-based turbines for reducing the temperature of metal substrates. Currently, state-of-the art TBCs are based on $7-8 \mathrm{wt} \%$ YSZ and in recent years ceramic compositions useful in thermal barrier coatings having reduced thermal conductivity are being explored. In the present study, 8wt\% yttria stabilized zirconia (YSZ) and lanthana doped YSZ plasma sprayable powders were prepared in the laboratory by a single step precipitation method and characterized. Both the powders had good flowability. These powders were plasma sprayed at three different critical plasma spray parameters. The coatings were characterized for phase, microstructure, wear resistance and thermal conductivity. Microstructure of the coatings showed that coatings had good adherence to the substrate. Plasma sprayed $8 \mathrm{wt} \% \mathrm{YSZ}$ and lanthana doped YSZ exhibited thermal conductivity values of 0.88 and $0.67 \mathrm{~W} \mathrm{~m}^{-1}$ $\mathrm{K}^{-1}$ respectively. This study shows that lanthana doping in YSZ helps in lowering the thermal conductivity and hence this coating may be a potential candidate for TBC application.

\section{INTRODUCTION}

. Thermal barrier coatings are highly advanced material systems that serve to insulate components from large and prolonged heat loads by utilizing thermally insulating materials which can sustain an appreciable temperature difference between the loadbearing alloys and the coating surface [Jiang, Levi]. In doing so, these coatings can allow for higher operating temperatures while limiting the thermal exposure of structural components, extending part life by reducing oxidation and thermal fatigue. The advantages of using ceramic thermal barrier coatings include increased engine power density, fuel efficiency, and improved engine reliability. The refractory nature of TBC materials such as yttria partially stabilized zirconia (YSZ) with melting points approaching or in excess of $3000 \mathrm{~K}$ requires ultrahigh temperature materials processing capabilities. A TBC should have low thermal conductivity [1-4], high temperature phase stability and resistance to sintering in order to maintain the pores present in the coating. A high thermal expansion coefficient is also necessary to minimize the thermal expansion mismatch between the coating and the metallic substrate. The of YSZ coatings with small amounts of $\mathrm{La}_{2} \mathrm{O}_{3}$ [5-17] has resulted in reduced thermal conductivity and resistance to sintering. Zhu et al. have developed a multicomponent defect clustering approach and doped YSZ with multiple dopants [8]. In all these studies a physical mixture of $\mathrm{La}_{2} \mathrm{O}_{3}$ and $\mathrm{YSZ}$ or spray dried powders were used for plasma spraying and seldom there are any reports on the preparation of plasma sprayable lanthana doped YSZ powders by a solution route and the properties of plasma sprayed coating thereof. The aim of the present work is (i) prepare $8 \mathrm{wt} \% \mathrm{YSZ}$ and lanthana doped $8 \mathrm{wt} \%$ YSZ (LDYSZ), (ii) characterize the powders for particle size, flowability and morphology (ii) to study the effect of lanthana doping on the microstructural and thermal properties of YSZ developed by the air plasma spraying technique. 


\section{EXPERIMENTAL}

In a typical experiment, $8 \mathrm{wt} \% \mathrm{YSZ}$ was prepared in-house by a single step co-precipitation technique as follows: Stoichiometric amounts of yttrium oxide (Loba) was dissolved in $100 \mathrm{ml}$ of $70 \%$ con.nitric acid (Merck ) and was added to $866.85 \mathrm{ml}$ of zirconium oxy nitrate solution (Hitech). The solution was mixed well and precipitated with $30 \mathrm{wt} \%$ ammonium carbonate (Loba) until the $\mathrm{pH}$ of the solution was in calcinations at $900^{\circ} \mathrm{C}$ for $24 \mathrm{~h}$. The calcined powder was crushed and sieved to remove very fine powders and used for plasma spraying without any further agglomeration step like spray drying. The prepared powder in the present study is designated as YSZ hereinafter. Similarly $5 \mathrm{wt} \% \mathrm{La}_{2} \mathrm{O}_{3}$ doped YSZ (LDYSZ) was also prepared.

The calcined powders were crushed gently by the use of a pestle and mortar to obtain free flowing powder. Further the powders were sieved to remove very fine and coarse powders. The crystalline phases present in both the prepared powders and the plasma sprayed coatings were confirmed by X-ray diffraction (XRD) using X-ray diffractometer (Bruker D-8 Advanced). Particle sizes were analyzed using laser light scattering method (Mastersizer 2000, Malvern Instruments). Flowability of the powder was measured using a Hall flow meter according to ASTM B213-97. The morphology of the powder and the surface and cross-sectional microstructures of the coatings were examined using field emission scanning electron microscope (FESEM, Carl Zeiss). The powder was plasma sprayed on a bond coat (Amdry 962 from Sulzer Metco) using air plasma spraying system (Sulzer Metco-9M). The coatings were performed on SS 304 substrates for characterization studies and aluminium metal substrates for thermal conductivity studies. The plasma spray parameters used for spraying bond coat, YSZ and LD YSZ powders are listed in Table-1. the range of 8-10. This was followed by filtration, drying and

coatings was measured, using FLASHLINE тм 5000 thermal diffusivity System (Anter Corporation, Pittsburgh, PA)., from room temperature to $900{ }^{\circ} \mathrm{C}$ and the values obtained at $900{ }^{\circ} \mathrm{C}$ is reported.

\section{RESULTS AND DISCUSSION}

Both YSZ and LDYSZ powders were blocky angular in shape (Fig.1). The particle size distribution of these powders obtained from particle size analysis is tabulated in Table-2. From Table-2 it is evident that doping lanthana in YSZ has resulted in a decrease in the particle size. The average agglomerated particle size for LDYSZ was $64 \mu \mathrm{m}$ compared to $83 \mu \mathrm{m}$ for YSZ. The exact role played by lanthana in inhibiting the grain growth is a subject of further investigation.

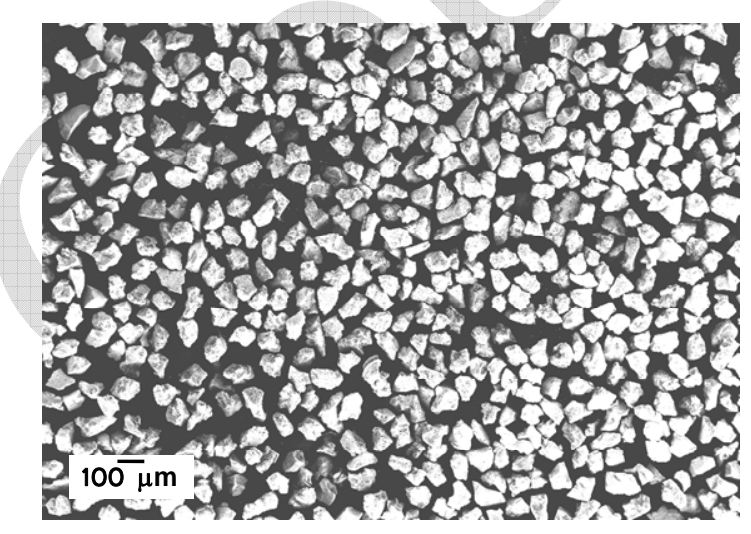

Fig.1. FESEM image of $\mathrm{La}_{2} \mathrm{O}_{3}$ doped $\mathrm{YSZ}$ particles

Table-2. Particle size distribution of powders used for plasma spraying

Powder source Particle size $(\mu \mathrm{m})$

\section{Table-1. Plasma spray parameters used for spraying} bond-coat and top-coat

\begin{tabular}{lll}
\multicolumn{3}{c}{ bond-coat and top-coat } \\
\hline Plasma spray parameters & Bond coat & $\begin{array}{l}\text { YSZ/ } \\
\text { LDYSZ }\end{array}$ \\
\hline Argon Flow (NLPM) & 40 & 42 \\
Hydrogen Flow (NLPM) & 7 & 8 \\
Amps (A) /Volts (V) & $550 / 60$ & $550 / 60$ \\
Carrier gas Flow (SCFH) & 15 & 15 \\
Pre Heat / Spray passes & $2 / 5$ & $2 / 14$ \\
Powder Feed rate (g/min) & 15 & 15 \\
Cooling air Pressure (bar) & 2 & 2 \\
Spray distance (cm) & 25 & 15 \\
Gun speed (mm/s) & 800 & 800 \\
\hline
\end{tabular}

For thermal conductivity studies, bond coat YSZ and LDYSZ were plasma sprayed on aluminium substrates and free-forms of the coatings were obtained by dissolving the substrate in $\mathrm{NaOH}$ solution. Thermal diffusivity $(\alpha)$ of the

\begin{tabular}{cccc} 
& $\mathbf{d}_{\mathbf{1 0}}$ & $\mathbf{d}_{\mathbf{5 0}}$ & $\mathbf{d}_{\mathbf{9 0}}$ \\
\hline & 50 & 83 & 134 \\
LYSZ & 50 & & \\
& & 64 & 106 \\
\hline
\end{tabular}

The powder XRD pattern of YSZ shows the presence of pure tetragonal phase. The XRD patterns of LDYSZ powder and coatings confirm the presence of pure tetragonal zirconia phase without any additional peaks corresponding to $\mathrm{La}_{2} \mathrm{O}_{3}$ (Fig.2). This shows that the method used for the preparation is a very opt process for the preparation of plasma sprayable powders without agglomeration steps like spray drying.

The cross-sectional FESEM images of the plasma sprayed coatings of both $8 \mathrm{wt} \% \mathrm{YSZ}$ and $\mathrm{La}_{2} \mathrm{O}_{3}$ doped $\mathrm{YSZ}$ shows excellent adhesion to the substrate. The coatings have dense, 
partially melted and unmelted zones (Fig. 3). The unmelted/partially melted zones exhibit nano size grains. The presence of partially melted and unmelted zones is due to the incomplete melting of the particles in the plasma flame.

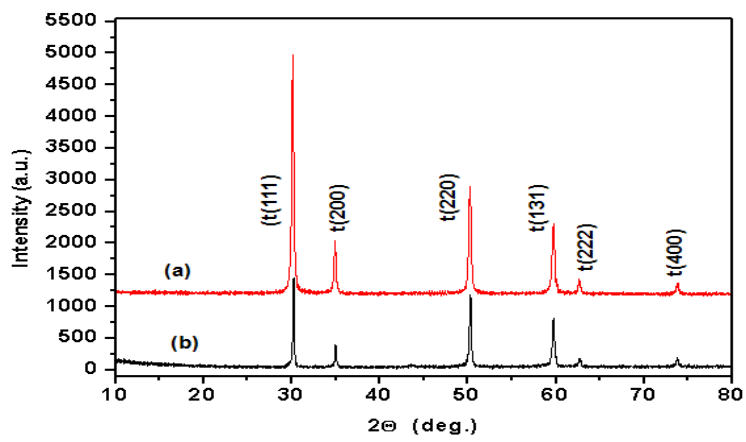

Fig.2 XRD pattern of $\mathrm{La}_{2} \mathrm{O}_{3}$ doped YSZ (a) powder and (b) plasma sprayed coating

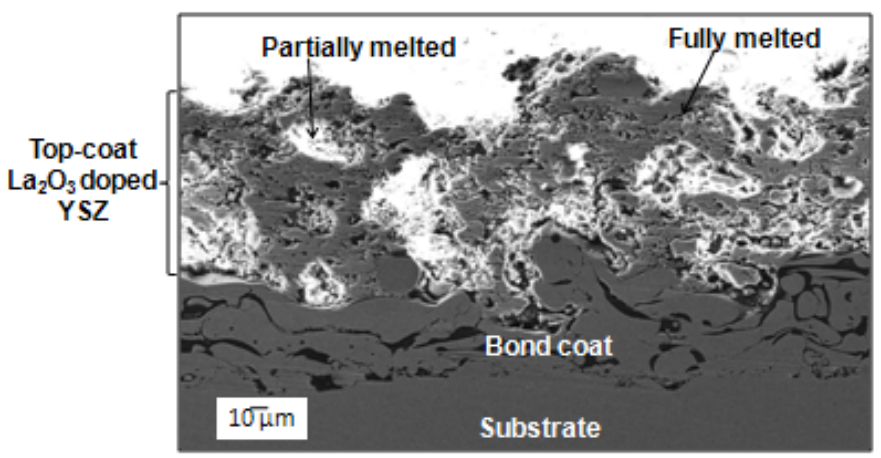

Fig.3. Cross-sectional FESEM image of TBC coating

The surface roughness of LDYSZ coatings are lower $(4 \mu \mathrm{m})$ when compared to $8 \mathrm{wt} \% \mathrm{YSZ}$ coatings $(8.5 \mu \mathrm{m})$. The lower roughness of LDYSZ coatings is attributed to the presence of more nanozones.

The thermal conductivity, thermal diffusivity and specific heat of the two coatings prepared under similar conditions are tabulated in Table- 3 .

Table-3. Thermal conductivity of plasma sprayed coatings

\begin{tabular}{|c|c|c|c|}
\hline Coating & $\begin{array}{l}\text { Thermal } \\
\text { diffusivity } \\
\left(\mathbf{c m}^{2} / \mathbf{s}\right)\end{array}$ & $\begin{array}{c}\text { Specific } \\
\text { heat } \\
(\mathbf{J} / \mathbf{K g} . \mathbf{K})\end{array}$ & $\begin{array}{c}\text { Thermal } \\
\text { conductivity } \\
\text { (W/m.K) }\end{array}$ \\
\hline YSZ & 0.0065 & 237.8 & 0.88 \\
\hline LD YSZ & 0.0028 & 162.8 & 0.67 \\
\hline
\end{tabular}

It is observed that the value of thermal conductivity decreases with the addition of lanthana. Phonons and their density are responsible for thermal conductivity of any material. Since the density of YSZ and LDYSZ is almost same so phonon will be responsible for the conductivity. This may be attributed to the higher porosity of the coatings. It is gratifying to note that the thermal conductivity of YSZ was also lower than 1 and this value is also lower than the reported value in the literature [18]. Thus the reduced thermal conductivity may be attributed to the higher porosity of the coating. This in turn is dependent on the porous nature of the synthesized particles.

\section{CONCLUSIONS}

This study has shown that by using chemical coprecipitation method and without the use of any agglomeration step and using suitable precursors, plasma sprayable YSZ and lanthana doped YSZ powders can be prepared without any impurities. These powders were suitable for plasma spraying and the obtained coating showed lot of porosity with many unmelted and partially melted particles. The thermal conductivity values are very low for these coatings. Doping YSZ with lanthana facilitated further decrease in thermal conductivity. To further substantiate the suitability of these coatings for TBC application, the thermal cycling capability of the coatings has to be evaluated.

\section{ACKNOWLEDGMENTS}

The authors acknowledge the financial assistance received from the Network project on Nanostructured Advanced Materials (NWP-00-51-01). The authors thank the Director, NAL for his constant encouragement. Help received from Bharath and Abhishek in the preparation of the powders is greatly acknowledged. Help received from Siju and G. Sreenivas in FESEM and XRD studies is acknowledged.

\section{REFERENCES}

[1] Jiang, X., Liu, C., Lin, F., 2007, "Overview on the Development of Nanostructured Thermal Barrier Coatings", Journal of Materials Science and Technology, Vol. 23, pp. 449-456.

[2] Levi, C.G.., 2004, "Emerging Materials and Processes for Thermal Barrier Systems", Current Opinions in Solid State and Materials. Science, Vol. 8, pp. 77-91.

[3] Kelly, M.J., Wolfe, D.E., Singh, J., Eldridge, J., Zhu, D.-M, Miller, R., 2006, "Thermal Barrier Coatings Design with Increased Reflectivity and Lower Thermal Conductivity for High-Temperature Turbine Applications", International. Journal of Applied Ceramic Technology, Vol. 3(2), pp. 81-93. 
[4] Clarke, D. R., Phillpot, S. R., 2005, Thermal Barrier Coating Materials, Mater.ials Today, Vol. 8 (6), pp. 22-29.

[5] Miller R. A., 1987, "Current Status of Thermal Barrier Coatings-An Overview," Surface and Coatings Technology, Vol. 3, pp. 1-11.

[6] F. Cernuschi, P.G. Bison, S. Marinetti, P. Scardi, 2008, "Thermophysical, Mechanical and Microstructural Characterization of Aged Free-Standing Plasma-Sprayed Zirconia Coatings", Acta Materialia, Volume 56, Issue 16, pp. $4477-4488$.

[7] Cao, X.Q., Vassen, R., Tietz, F., Stoever, D., 2006, “New Double-Ceramic-Layer Thermal Barrier Coatings Based On Zirconia-Rare Earth Composite Oxides", Journal of the European ceramic society Vol. 26, pp. 247-251.

[8] Paul, S., Ciptria, A., Tsipas S.A., Clyne, T.W., 2009, Sintering Characteristics Of Plasma Spayed Zirconia Coatings Containing Different Stabilizers, Surface and coatings Technology, Vol. 203, pp.1069-1074.

[9] Tsipas S.A., 2010, Effect of Dopants on the Phase Stability of Zirconia based plasma sprayed TBC's, Journal of the European Society, Vol. 30, pp. 61-72.

[10] Zhu, D., Nesbitt, J.A., Barrett, C.A., Mccue, T.R., Miller, R.A., 2004, "Furnace Cyclic Oxidation Behavior Of Multicomponent Low Conductivity Thermal Barrier Coatings" Journal of Thermal Spray Technology, Vol. 13, pp. 84-92.

[11] Kulkarni, A., Vaidya, A., Goland, A., Sampath, S., Herman, H., 2003, Processing Effects On Porosity Property Correlations In Plasma Sprayed YSZ Coatings, Materials and Engineering A, Vol. 359, pp. 100-111.

[12] Nicholas, C., Nicolaie, M.,; Xin-Hai L., ; Aurélien, T.,; Mitch, D., "Next Generation Thermal Barrier Coatings for the Gas Turbine Industry", Journal of Thermal Spray Technology, Vol. 20, Issue 1-2, pp. 108-115.

[13] Matsumoto, M., Takayama, H., Yokoe, D., Mukai, K., Matsubara, H., Kagiya, Y., Sugita, Y., 2006, Thermal Cycle Behavior of Plasma Sprayed $\mathrm{La}_{2} \mathrm{O}_{3}, \mathrm{Y}_{2} \mathrm{O}_{3}$ Stabilized $\mathrm{ZrO}_{2}$ Coatings, Scripta Materialia, Vol. 54, pp. 2035-2039.

[14] Matsumoto, M., Aoyama, K., Matsubara, H., Takayama, K., Banno, T., Kagiya, Y., Sugita, Y., Mukai, K., Matsubara, H., Kagiya, Y., Sugita, Y., 2005, Thermal conductivity and phase stability of plasma sprayed $\mathrm{ZrO}_{2}-\mathrm{Y}_{2} \mathrm{O}_{3}-\mathrm{La}_{2} \mathrm{O}_{3}$ coatings, Surface and coatings Technology, Vol. 194, pp. 31-35.
[15] Matsumoto, M., Kato, T., Yamaguchi, N., Yokoe, D., Matsubara, H., 2009, Thermal Conductivity And Thermal Cycle Life Of $\mathrm{La}_{2} \mathrm{O}_{3}$ And $\mathrm{HfO}_{2}$ Doped $\mathrm{ZrO}_{2}-\mathrm{Y}_{2} \mathrm{O}_{3}$ Coatings Produced By EB-PVD, Surface and coatings Technology, Vol. 203, pp. 2835-2840.

[16] Y. Liu, Y.F. Gao, S.Y. Tao, Zhou, X.M., Li, W.D., Luo, H.J., Ding, C.X., 2008, "Microstructure of Plasma Sprayed $\mathrm{La}_{2} \mathrm{O}_{3}$-Modified YSZ Coatings", Journal of Thermal Spray Technology, Vol. 17, pp. 603-607.

[17] Y. Liu, Y.F. Gao, S.Y. Tao, X.M. Zhou, H.J. Luo, 2009, " $\mathrm{La}_{2} \mathrm{O}_{3}$-Modified YSZ Coatings: High-Temperature Stability And Improved Thermal Barrier Properties", Surface and Coatings Technology, Vol. 203, pp.1014-1019.

[18] Rauf, A., Yu, Q., Jin L., Zhou, C., 2012, Microstructure And Thermal Properties Of Nanostructured Lanthana-Doped Yttria-Stabilized Zirconia Thermal Barrier Coatings By Air Plasma Spraying, Scripta Materialia, Vol. 66, pp. 109-112. 


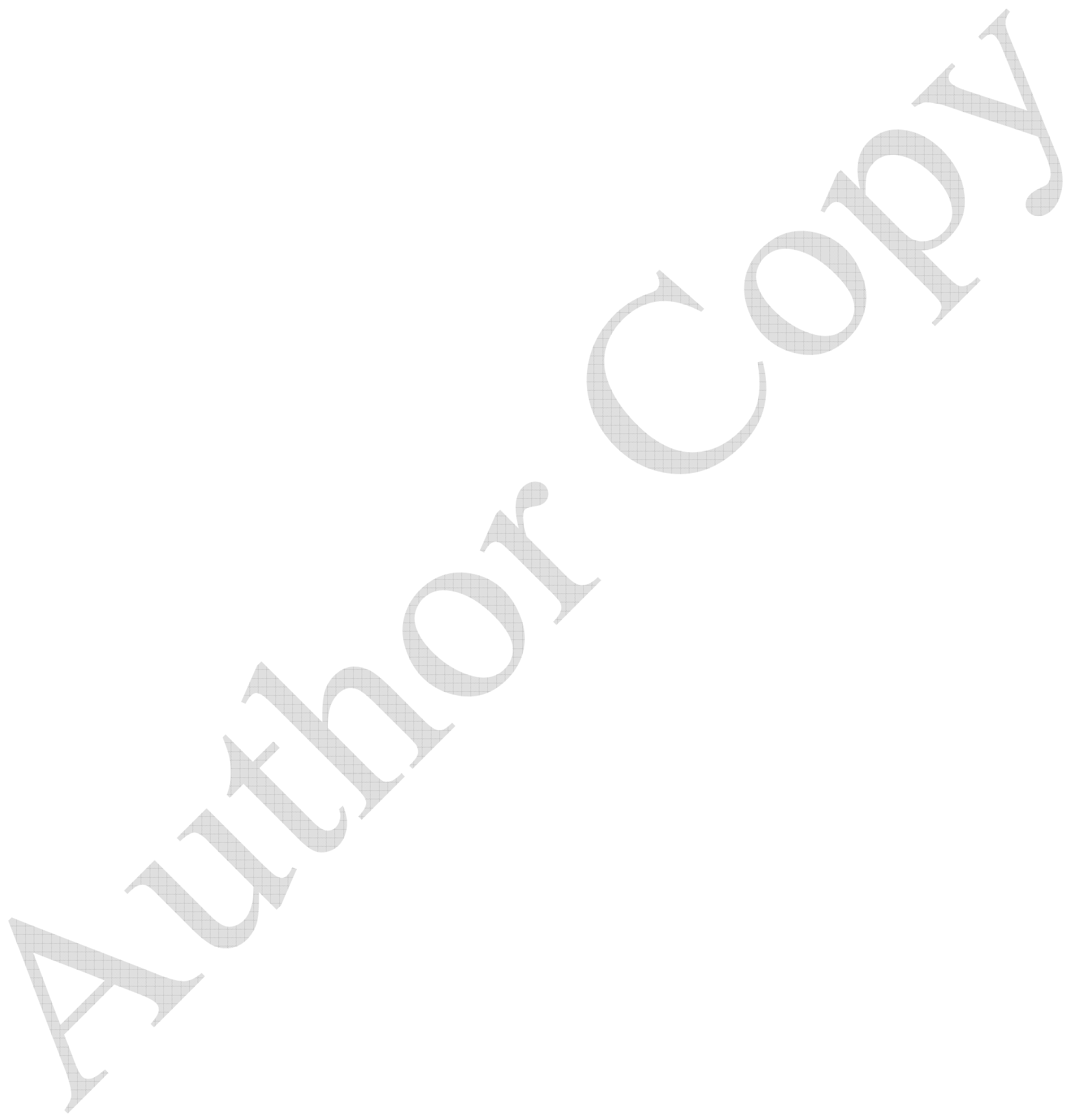

